examination of patients as well as of animals should be close to the clinical services, and even directly attached to the ward or out-patient department.

Although many valuable discoveries may still be anticipated from those actively engaged in the practice of medicine and surgery, Sir Thomas expressed his conviction that in many directions advances may more readily come from men who are able to give their whole time to research, unhampered by routine duties. Appointments for clinical research are therefore required, and no more suitable place for such appointments could be found than within a university, where persons engaged in research would enjoy the stimulus derived from teaching and find a congenial atmosphere.

Sir Thomas then passed on to the subject of the medical education of to-day, in which, as is generally agreed, he holds there are grave defects. The curriculum is overloaded not only by the preliminary sciences, including anatomy, physiology and general pathology, but also on the clinical side.

The plan suggested by Sir Thomas Lewis as a remedy is as follows: There should be a first course consisting of the outlines of human anatomy and physiology, with special stress laid on what is immediately applicable to the study of disease. The second course, which would not be compulsory for all medical students but would be suitable to a science degree or to those who intended to take up physiology, pathology or clinical science as a career, would be one of more advanced physiology. The third or final course would consist partly of general and practical instruction along existing lines, emphasis being laid on all that is essential to general practice. The teaching should be mainly concerned with common diseases and remedies of proved value and ready application. The outlines of clinical science should be included in this course, which would be taken by all medical students, but higher examinations would be held by the Royal Colleges and possibly by the universities, and there might be room for a university degree in clinical science for those who proposed to adopt an academic career.

As to the final stage of the student's preparation for medical practice, Sir Thomas granted that the best teacher is the man in active practice, who not only understands disease and its treatment in detail but is also able to manage sick people and their friends. These accomplishments, however, do not qualify the teacher for the post of university professor in clinical science, whose duties should rather be to deal with the principles and problems of clinical science, and with the patients only to exemplify specific points. The former would include the causes of disease, the principles of hereditary transmission of human diseases, the reaction of man to his environment, physical injuries and chemical poisons, the meaning and effects of infection, the significance of sexual, racial and other predispositions to disease, and the origin of new growths in man.

In conclusion, Sir Thomas repeated that it is largely within the power of the universities to establish clinical science on the same basis as the allied sciences of physiology and pathology, as distinct from the practical art of medicine.

\title{
British Chemical Abstracts
}

$\triangle$ LMOST exactly eight years ago, the appear$A$ ance of the first annual index volume, covering the whole of the abstracts in pure and applied chemistry prepared and published under the direction of the Bureau of Chemical Abstracts during 1926, afforded us an opportunity of referring appreciatively to a scheme which has since proved a remarkably successful co-operative enterprise.

The Chemical Society, which since 1871 had undertaken the task of supplying abstracts of papers dealing with pure, physical, inorganic, organic, analytical, mineralogical and biological chemistry, and the Society of Chemical Industry, which had similarly surveyed applied chemistry since 1882, had for many years maintained mutually helpful contact between their respective abstracting organisations; in 1924, however, these two Societies united in establishing the Bureau of Chemical Abstracts, charging the new body with the task of controlling both the preparation and the publication of abstracts in all branches of pure and applied chemistry, and of securing such unification as might prove practicable. By the end of 1925 their efforts had been so far successful that consent had been secured to a common format for the two sections, known as British Chemical Abstracts $A$ and $B$, respectively, a considerable amount of overlapping material which had previously appeared in somewhat different forms in both sections was eliminated, and the publication of an annual index envisaging the whole range of pure and applied chemistry was undertaken. A few, of course, shook their heads disapprovingly 
at this breach with tradition, and there was some regret-admittedly largely sentimental-at the disappearance of the familiar octavo format; but experience has amply demonstrated the wisdom of the decisions then taken, and, moreover, both American and French chemical abstract publications have since joined the ranks of the 'double column quartos'.

The organisation set up by the Bureau immediately on its establishment had by that time proved to be operating smoothly and efficiently, and the editor, specialist assistant editors, abstractors and indexer settled down to a task of annually increasing magnitude with the firm intention of making British Chemical Abstracts the world's best journal of its kind. While there is no means of taking the exact measure of their success, there can be little doubt that, despite the need to trim canvas on occasion the better to ride out financial storms, the Bureau and its staff have provided the English-speaking world with an abstract journal which for accuracy, conciseness, promptitude, relevance and catholicity can fairly claim a place certainly not less honourable than that of any other such journal in any language.

During the past five years, there has been proceeding, concurrently with, and independently of, the preparation of the annual joint indexes, work which has now borne fruit in the completion of a collective index covering the period 1923-32*. This publication, which so far as the Chemical Society is concerned is a continuation of a series of collective indexes dating from 1841, and so far as the Society of Chemical Industry is concerned includes the abstracts published independently in that journal in 1923 , is a quarto production of some 2,100 pages referring to authors and 1,766 pages referring to subjects; it has been estimated that the number of entries must considerably exceed half a million. In order to ensure homogeneity it was found necessary to re-index the abstracts in applied chemistry published before 1926, for in the corresponding annual indexes a somewhat different system had been employed. Moreover, the varying spelling of countless Russian, Indian and Japanese authors' names has been standardised so far as possible, although in some cases the decision has necessarily been purely arbitrary; for although the transliteration of Russian characters is consistent when carried out according to the Bureau's scheme, the frequency with which Russian authors publish in other

* Collective Index of British Chemical Abstracts. (A) Pure Chemistry and (B) Applied Chemistry, 1923-1932, including the Abstract published with the Journal of the Chemical Society and the Journal of the Society of Chemical Industry, during 1923-1925. Part 1: Index of Authors. A-K. Pp. 1092. I-Z. Pp. 1093-2101. Part 2: Index of Subjects. Pp. 1766. (London: Bureau of Chemical Abstracts, 1935.) £8. languages leads at times to their names being transliterated almost out of recognition. Such complications and obscurities as might arise from changes in nomenclature during the period under review, from inadequate identification of authors by their surnames alone, and from the massive entries attributable to the largest industrial firms, have been foreseen and avoided so far as is possible.

In the 'author index', series papers by the same author or authors are collected under one main title, with the years and pages placed after the sub-titles at the end of the entry. The general arrangement of the entries is described in the explanatory notes. The volume contains a greatly extended list of radicals, whilst a new and welcome feature is the chart indicating the numbering of positions in ring systems.

Could scientific achievement be measured in terms of the weight and volume of an index, there would be ample cause for satisfaction on the part of even the most diligent among the workers in this ten-year period. But the mounting figures which record increases in the number of chemical abstracts published annually still reflect a rapid rate of increase in the volume of new material which finds its way into the periodical and patent literature. Figures, of course, can be made to prove almost anything; but an increase from 25,500 in 1932 , the last year of the decade, to 29,400 published in 1934 is perhaps sufficient evidence for the assumption that the production of decennial indexes in future will be an even heavier task. The corresponding annual indexesthat for 1934 has just been issued-occupy 578 and 692 pages, respectively.

Provocative, or perhaps merely vacuous, statements regarding the desirability of calling a halt in the publication of chemical literature are still heard ; such retrogression is clearly impossible ; but on the other hand the desirability of brevity and precision in scientific publications cannot be too insistently urged. So far as abstracts play a part in maintaining the march of progress, we can profitably repeat what we have said before: that since the rate of advance in any branch of knowledge so largely depends on an adequate acquaintance with the experimental results and theoretical views forming the starting point of any new research, the efficiency of the abstracting and indexing service is a matter which closely concerns every investigator, teacher and student. The success attained by the Bureau of Chemical Abstracts is a demonstration of what can be done when interested parties pool their resources, and it should encourage co-operation over an even wider field. 